\title{
Violência doméstica contras as mulheres negras no Brasil a partir de abordagens feministas negras e decoloniais
}

Ana Karolina Matias Emydio ${ }^{1}$, Fernanda da Silva Lima² e Iara Schardosin Bayma de Menezes ${ }^{3}$ doi.org/10.47585/nemtudosaorosas1 


\section{Introdução}

Inicialmente, considera-se importante situar que este breve ensaio foi construído a seis mãos, de forma interdisciplinar e guiadas por um objetivo comum. Nesta escrita, somos duas mulheres brancas acadêmicas ainda em formação e uma mulher negra doutora. Os encontros e as trocas partilhadas sobre pensar os feminismos de forma crítica nos levou a esta escrita, potencializada pelo espaço comum em que seguimos nos formando - o Núcleo de Estudos em Gênero e Raça/Unesc, coordenado de forma partilhada pelas professoras Fernanda da Silva Lima (Direito) e Lucy Cristina Ostetto (História). O NEGRA constitui-se num espaço de pesquisa-ação, cuja abordagem é decolonial e afrocentrada. Organiza-se a partir do diálogo e enquanto espaço de luta, de (re)existência, afetividade, acolhida e de produção de epistemologias outras.

Todas nós estamos estudando os feminismos negros e decolonial, tencionando os conhecimentos produzidos a partir de ideias eurocêntricas estruturadas em um universalismo abstrato que exclui saberes outros (KILOMBA, 2019). Partindo deste ponto de vista, propomos expor temas urgentes numa linguagem comprometida em romper com o academicismo eurocentrado, sempre ancorado sob uma falsa neutralidade mantenedora de narrativas hegemônicas e universalizantes. Por isso, nos insurgimos e reafirmamos um pensar intelectual e militante e, no que tange aos estudos sobre as mulheres, encontramos nos feminismos negros e decoloniais o potencial libertador, não só por se constituírem por meio da luta, mas por que fraturam a estrutura colonial de gênero vigente. Assim, é possível fraturar a estrutura patriarcal, cisheteronormativa, colonial, que habita o espaço acadêmico e segue reproduzindo contextos coloniais que reforçam estruturas de poder (LIMA; SOUSA, 2020).

Como já afirmou Talíria Petrone (2019), “[...] o feminismo é uma urgência no mundo, no entanto, nem todo feminismo é capaz de libertar todas as mulheres, e não é mais possível aceitar que o feminismo deixe corpos pelo caminho." Não é mais possível teorizar de forma universal sobre as lutas feministas e as questões de gênero desarticuladas de outras matrizes de opressão, como a raça, a classe, a sexualidade, entre outras. A contra-narrativa das mulheres negras apresenta-se contra o 'teorizar' excludente, que tenta silenciá-las e invisibilizá-las.

A universalização de 'conhecimentos' fez com que muitas mulheres não aderissem ao movimento feminista liberal - dito inicial - que dizia ser um espaço de afirmações e representatividades (HOOKS, 2019). Assim, no seio das lutas feministas existiam diversas questões emergindo: Afinal, para quem é o feminismo? Como a história é contada? Quem a conta? E quais as consequências de um movimento com raízes excludentes e coloniais?

Enfatizar o debate através do feminismo decolonial é incentivar a ruptura epistemológica, política, eurocêntrica dos contextos que foram universalizados e intensivamente apagam histórias e distorcem narrativas. O feminismo negro e decolonial abre espaços para que seja possível refletir diversidades, saberes outros e também novas abordagens culturais, econômicas e sociais, capazes de fraturar a ideologia simplista que silencia outras formas de produzir conhecimento (FEMENÍAS, 2007).

Dito isso, partindo de movimentos feministas no Brasil, novos espaços foram ganhando evidência. Uma das reivindicações partiu das denúncias sobre as violências domésticas e familiares vivenciadas por diversas mulheres em espaços considerados privados (KIEFER; SEABRA; JÚNIOR, 2016). Após tensionamentos oriundos dos movimentos feministas e sociais, ocorreu a criação da Lei Maria da Penha, no ano de 2006, para acolher as mulheres vítimas de violências domésticas.

Entretanto, apesar da importância do marco normativo, algumas mulheres passaram a problematizar o alcance jurídico que revela as dificuldades das mulheres negras no acesso às ferramentas legais oferecidas pela Lei Maria da Penha. Da mesma forma, nos casos de violência doméstica, o sistema de justiça, dado o seu modelo universal, segue assentado numa base estruturalmente racista (CARNEIRO, 2017).

Diante disso, o objetivo deste trabalho é evidenciar as epistemologias feministas negras e abordagens decoloniais em espaços onde a construção de normas geram impacto na vida das mulheres, principalmente evidenciando as ferramentas jurídicas que conformam situações racistas. Desdobra-se 
esse objetivo em outros três tópicos: a) Enfatizar a história dos movimentos feministas partindo das produções e inquietações presentes nas abordagens dos feminismos negros e decoloniais; b) Destrinchar a ferramenta de proteção às mulheres vítimas de violência doméstica no Brasil, expondo suas fragilidades com relação às mulheres negras; c) Tencionar o descaso com as pautas raciais no sistema judiciário, evidenciando as amarras racistas que impedem uma aplicação integral de normas para proteção das mulheres negras no Brasil. A pesquisa parte da abordagem dedutiva, cujo levantamento foi feito por meio de análise bibliográfica e levantamento documental.

\section{Reflexões sobre os feminismos}

É na perspectiva de ser um pensamento crítico construído na luta que o feminismo negro e decolonial se apresentam potentes e contra-hegemônicos. Rompem com as noções genéricas e abstratas do que é 'ser mulher', fraturam a noção de opressão comum (HOOKS, 2019) entre as mulheres e tecem críticas ao patriarcado universal. Para Lugones (2008), as teorias generalizantes não são adequadas e nem representativas das necessidades do grupo de mulheres não-brancas, e sim, fontes de dominação e propagação da colonialidade.

Infelizmente, em muitos espaços acadêmicos não há o tensionamento sobre o conhecimento colonizado. Logo, mulheres que sofrem opressões de raça, classe, sexualidade não têm suas categorias introduzidas nesses espaços, e a hierarquia de saberes continua sendo mantida (MELO et al, 2019).

A supremacia branca, além de propositalmente dificultar a articulação entre as mulheres negras em espaços de visibilidade, elimina a possibilidade dessas mulheres falarem a partir do local social em que estão inseridas, pois há um processo de 'representatividade' em jogo que não considera as questões raciais. As feministas liberais não compreendem as intersecções entre raça, gênero, classe ou outras formas de opressão, pois se embasam em narrativas coloniais, excludentes, de falsa representatividade cujo interesse é manter o status quo. Com isso, os estudos feministas não se comunicam com grupos de mulheres que não pertencessem às esferas privilegiadas (HOOKS, 2019).

Os espaços de falsa representatividade e superioridade branca nos movimentos feministas já eram denunciados por mulheres negras que enfrentavam as opressões sendo alvo não só de homens brancos, mas também de mulheres brancas. Ao contrário do que algumas feministas brancas procuram estabelecer, o feminismo decolonial e o feminismo negro não são grupos que visam apenas a tensionar o movimento feminista liberal, mas sim partir de uma própria realidade perspectiva, narrativa e construção, consequentemente desmantelando a falsa representatividade do movimento feminista liberal (MELO et al, 2019).

A exclusão das demandas que denunciam o racismo como estruturante das violências reflete o fracasso do feminismo branco, pois replica, sustenta e não enfrenta o racismo. Algumas feministas brancas estão tão interessadas em refletir sua inserção na categoria enquanto oprimidas pelo sistema patriarcal que não refletem espaços outros, acabam não reconhecendo seu papel, seja como vítima, opressora ou reprodutora do racismo em uma sociedade colonialista e supremacista branca (KILOMBA, 2019).

Segundo Kilomba (2019), esse modelo de patriarcado, introduzido por um modelo eurocêntrico, sustenta as intersecções de opressão que mulheres negras enfrentam cotidianamente. Essa estrutura de opressão tem impossibilitado que suas vozes sejam ouvidas. A legitimidade de dar voz é algo que a supremacia branca tem filtrado e operado por meio de discursos coloniais em que classifica determinados grupos como apropriados ou não para falar e existir.

As intelectuais e ativistas [brancas] tendem a reproduzir a postura do feminismo europeu e norteamericano ao minimizar, ou até mesmo deixar de reconhecer, a especificidade da natureza da experiência do patriarcalismo por parte de mulheres negras, indígenas e de países antes colonizados. (GONZALEZ, 2008, p. 36).

O feminismo decolonial, conforme Castro (2020), busca romper com o que se considera o único ponto de partida, ou seja, a história única e colonialista. É preciso reivindicar o protagonismo 
das mulheres focando nas suas experiências que são frutos de resistência à violência racista e colonial. Assumir um compromisso com o feminismo decolonial é reconhecer que as estruturas eurocêntricas estão igualmente amarradas ao racismo e ao gênero.

Sobre isso, Lugones (2008) analisa a diferença colonial, em seus aspectos materiais, econômicos, políticos e culturais, principalmente nos aspectos relativos à colonialidade do poder, elaborando o conceito de 'sistema moderno/colonial de gênero' que despreza as categorias de raça e classe em suas análises sobre mulheres colonizadas. Por isso, é preciso criticar modelos de conhecimento disseminados a partir da leitura colonial. Leitura colonial essa que é traçada dentro de um feminismo civilizatório, ou seja, aquele que impõe os padrões universais contribuindo para a perpetuação de ideologias dominantes sobre raça, classe e gênero.

A proposta decolonial propõe um desprendimento da colonialidade de poder, do ser e do saber. Esse desprendimento é entendido por meio do reconhecimento e legitimação dos saberes subalternizados, ou seja, reconhecer os pontos de partida que são interpretados de acordo com as experiências fora do espectro colonial, patriarcal, capitalista, branco e dominante. Trata-se de valorizar aquilo que é produzido de forma coletiva, sem colocá-lo como universal. Também é importante desprender dos discursos e estratégias que seguem objetificando grupos sociais como o 'outro', e assumir um compromisso com a descolonização de forma prática (CURIEL, 2018).

É neste sentido que as feministas decoloniais e, no nosso ponto de vista, o feminismo negro - ou a luta das mulheres negras no Brasil , têm diuturnamente enfrentado e resistido à opressão epistêmica, seja na academia ou em decorrência dos processos de luta (LIMA; SOUSA, 2021). Estamos fraturando e (re)posicionando a luta das mulheres negras a partir do seu próprio ponto de vista e de uma luta que é, sobretudo, coletiva (COLLINS, 2016).
No Brasil, as lutas das mulheres negras tornam-se mais visíveis a partir do final da década de 1970, coincidindo com o momento de abertura democrática e a inserção no debate público das pautas dos chamados 'novos movimentos sociais'. Neste contexto é criado o Movimento Negro Unificado em 1978 e, no ano seguinte, ocorre o I Encontro Nacional de Mulheres com a divulgação de um manifesto por parte das mulheres negras. Em 1985, o Brasil sediou o III Encontro de Mulheres Latino Americanas em Bertioga/SP e, assim como em outros espaços ${ }^{4}$, as mulheres negras foram pouco atendidas em suas reivindicações. Em 1988, reuniram-se no Rio de Janeiro e promoveram o I Encontro Nacional de Mulheres Negras, colocando o debate do racismo, do sexismo e do classicismo - além de outras opressões - na ordem do dia (MOREIRA, 2007).

Autoras como Rosália Lemos e Núbia Regina Moreira pesquisam sobre os movimentos e coletivos de mulheres negras há muito tempo. Consideram o NZINGA (Coletivo de Mulheres Negras do Rio de Janeiro), no ano de 1983, a primeira entidade do movimento feminista negro - mesmo a terminologia ainda não sendo invocada à época.

A criação do NZINGA é o marco para o Feminismo Negro contemporâneo no Brasil devido seu posicionamento político nas relações de gênero e raça. E vale destacar a relevância da iniciativa da ativista, professora mestre e a política, Lélia Gonzalez que iria iniciar a sistematização do pensamento feminista negro e faria de sua produção intelectual, un veículo de militância e de repúdio austero à Democracia Racial no Brasil. Em seus textos, encontram-se a denúncia do racismo, do sexismo, das discriminações por orientação sexual e suas incidências sobre as mulheres negras. Assim como as escritoras dos anos 1940 e 1950 Lélia pensava nos sistemas de opressão interseccionados [...]. (LEMOS, 2016, p. 21).

Do mesmo modo, Angela Figueiredo (2020) narra como o feminismo negro vai se

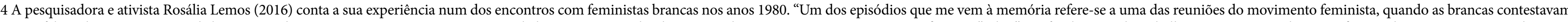

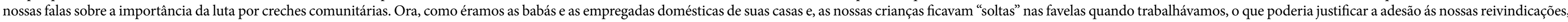
mas "elas" foram aliadas às nossas propostas. A luta por creches comunitárias era uma bandeira tão importante para as mulheres negras moradoras das áreas pobres, que assumíamos com toda a força em nossa ação política." (p. 19). 
consolidando nos últimos anos no Brasil, seja como campo de atuação política e/ou teórica, fraturando o campo dos estudos feministas hegemônicos e abrindo espaço para as disputas de outras narrativas e epistemologias que levem em consideração a posição das mulheres negras e suas múltiplas opressões. Com isso, a autora demonstra que o alargamento do campo de estudos sobre o feminismo negro no Brasil também tem sido possibilitado pelas traduções de obras importantes e que recentemente conquistaram apreço das grandes editoras, embora, critica ela, autores e autoras negros brasileiros ainda tenham pouco acesso às mesmas (LIMA; SOUSA, 2021).

\section{Violência doméstica e a Lei Maria da Penha}

Conforme Santos et al (2019), a violência doméstica é manifestada por meio de qualquer ação ou omissão contra mulheres baseada no gênero e ocasione danos físicos, sexuais, psicológicos, morais, patrimoniais ou leve à morte. Essa violência também se configura como uma forma de dominação, exploração e opressão, em que as mulheres passam por um processo de invisibilidade. Em situações onde há violência, mulheres são forçadas a abrir mão da sua performance enquanto sujeito.

Por conta dessas violências, e de todo o processo de luta das mulheres, foi criada no Brasi em 2006 a Lei no 11.340, também conhecida como Lei Maria da Penha, que simbolizou uma conquista marcante do movimento feminista brasileiro, que demonstrou uma interferência na ação política questionando como o Estado responsabilizava-se diante das violências diárias contra mulheres. O ponto de partida da Lei é a crítica de como se estruturam as relações de gênero (CARNEIRO, 2017).

A Lei Maria da Penha representou um enorme avanço na exigibilidade de atuação pública no enfrentamento à violência contra a mulher, pois além de tipificar, definir e estabelecer as formas de violência doméstica contra a mulher, estabeleceu medidas de assistência, proteção e atendimento humanizado às vítimas, além de criar mecanismos para protege-las e coibir a violência (CARNEIRO, 2017). Portanto, a lei é uma ação afirmativa de enfrentamento a uma condição histórica de violência, discriminação e opressão das mulheres. A pesquisadora Carmem Campos (2015) explica os serviços e ferramentas da Lei:

A rede de serviços para mulheres em situação de violência (rede especializada) é constituída por Centros de Atendimento à Mulher em situação de violência, Casas-abrigo, Casas de Acolhimento Provisório, Delegacias Especializadas de Atendimento à Mulher, Núcleos da Mulher nas Defensorias Públicas, Promotorias Especializadas, Juizados Especiais de Violência Doméstica e Familiar contra a Mulher, Central de Atendimento à Mulher (180), Ouvidoria da Mulher, Serviços de saúde voltados para o atendimento aos casos de violência sexual e doméstica, Posto de Atendimento Humanizado nos aeroportos e Núcleo de Atendimento à Mulher nos serviços de apoio ao migrante.

Conforme a autora, apesar do grande marco, alguns problemas passam a surgir. Um deles é a localização dos serviços de proteção às mulheres, que é limitada, pois a maioria dos centros de atendimento encontram-se inseridos em capitais, não abarcando zonas rurais, distantes ou com número relativamente pequeno de habitantes. Outra situação que dificulta um atendimento com melhor preparo é a falta de comunicação entre os setores de atendimento. Tal falta de articulação dificulta o acesso das mulheres e, consequentemente, a implementação da Lei Maria da Penha.

Outra dificuldade localizada, é a insuficiência de delegacias especializadas no atendimento às mulheres. Por se tratar de experiências violentas, sensíveis e doloridas, a existência de delegacias especializadas é fundamental. Como se não bastasse, a estrutura das delegacias é precária, faltando recursos, ferramentas, materiais, demonstrando empecilhos estruturais à efetivação da Lei. Além das delegacias estarem despreparadas, as casasabrigos direcionadas às mulheres em situação de grave ameaça ou risco de morte não estão inseridas em todos os estados brasileiros, sequer há casas-abrigo em todos os municípios demonstrando uma preocupação relacionada mais a cumprir normas do que se comprometer com o atendimento às mulheres (CAMPOS, 2015).

Apesar de ser uma rede importante, Campos (2015) explica que algumas mulheres relatam sofrer violências dentro da própria instituição, cujo local deveria significar apoio e segurança. Ademais, em algumas 
casas-abrigo são ofertados cursos profissionalizantes, porém, ao situar os cursos oferecidos para incentivar a atividade econômica, percebe-se que não há, posteriormente, uma inserção das mulheres egressas no mercado de trabalho, trazendo a elas ainda mais insegurança, sofrimento e desgaste. O descaso evidenciado em relação aos atendimentos para as mulheres nas delegacias, casas-abrigo, centros de referência e juizados especializados - além das outras redes que trabalham conjuntamente com casos de violência doméstica - deve ser lido como uma forma de invisibilidade, principalmente quando se percebe que as mulheres mais afetadas pela má prestação de serviço são as mulheres negras (CAMPOS, 2015).

Algumas autoras já discutem estudos que revelam dificuldades das mulheres negras no acesso às ferramentas legais e ao sistema de justiça nos casos de violência doméstica. Algumas mulheres acabam denunciando as instituições que realizam atendimento jurídico, pois nesses espaços também ocorrem violações dos seus direitos, de modo a desumanizá-las e silenciá-las, tirando autonomia, vozz e humanidade (CARNEIRO, 2017).

Conforme o Fórum Brasileiro de Segurança Pública (FBSP) de 2019, nos casos de violência doméstica parte significativa envolve alguém próximo da vítima: $76,4 \%$ dos agressores são conhecidos, sendo $39 \%$ parceiros e ex-parceiros, e 14,6\% parentes. Esses dados revelam a forma como a violência se estabelece já na juventude e pode se agravar ao longo do tempo, especialmente quando a vítima não rompe a relação abusiva.

Essa desumanização é vivenciada não só dentro de um espaço que deveria ser seguro, como também nos órgãos estatais que deveriam enfrentar eficazmente a violência doméstica contra as mulheres negras. Suelaine Carneiro (2017, p. 9) pontua:

Analisando os números sobre a violência contra as mulheres no Brasil, entendemos que as mulheres negras não contam efetivamente com o apoio do Estado. Diante de todo o aparato jurídico que elencamos anteriormente, as mulheres negras dependem de si mesmas para viver uma vida sem violências.
Dados do primeiro semestre de 2017 retirados dos atendimentos relacionados ao Ligue 180 registraram 555.634 ligações, dessas quase 68 mil eram relatos de violência, sendo 51,06\% violências físicas, 31,10\% violências psicológicas, 6,51\% violência moral, 4,86 \% Cárcere privado, 4,3\% violência sexual, $1,93 \%$ violência patrimonial e $0,24 \%$ relacionados ao tráfico de pessoas. Nessas ligações, 59,71\% das mulheres que relataram casos de violência eram negras (CARNEIRO, 2017).

Cabe destacar que, no atendimento nos sistemas judiciários, as mulheres brancas recebem determinado atendimento (bom atendimento comparado às mulheres negras), enquanto as mulheres negras são deixadas de lado, num limbo dificilmente visado. Dentro da estrutura judiciária há seletividade, que pode ser analisada pelas lentes da segregação em que as taxas de violência contra as mulheres negras tendem a aumentar ${ }^{5}$. Sabe-se que essas situações têm nome, forma, origem e reprodutores, são facetas do racismo institucional e estrutural implantadas no sistema de justiça brasileiro (CARNEIRO, 2017).

Embora tenhamos abordado anteriormente o conceito de racismo, de forma ampla, é importante destacar as definições de racismo estrutural e institucional trabalhadas por Almeida (2018). O autor explicará o racismo estrutural como aquele que naturaliza as desigualdades raciais e atua como 'carro chefe' do racismo, já que é o que conduz, viabiliza e aperfeiçoa suas facetas para seguir desumanizando a população negra. Tal aperfeiçoamento é demonstrado por meio da criação de condições sociais que designam e normalizam a discriminação racial.

Já o racismo institucional, embora caracterizado de forma mais 'sutil', não é menos agressivo. As manifestações ocorrem por meio do tratamento discriminatório por conta da raça, ou seja há imposição de barreiras que dificultam o acesso das pessoas negras em espaços institucionais. Além disso, há negligência, exclusão e ações conjuntas que colocam pessoas negras em espaços desumanizados e precários, e pessoas brancas em posição de poder e superioridade. Assim, o racismo institucional é a expressão e materialização do racismo estrutural (ALMEIDA, 2018).

Mulheres negras aparecem em indicadores que apontam crescimento nas agressões físicas, demonstrando que não estão recebendo as proteções asseguradas pela Lei 11.340/06. O crescimento de assassinatos contra essas mulheres, até 2013 , teve um aumento de $54,2 \%$, evidenciando obstáculos 
maiores no acesso à justiça quando comparado às mulheres brancas (SEVERI, 2017).

A violência contra as mulheres negras no espaço público, em contraposição à violência contra as mulheres brancas que na maioria das vezes se restringe ao espaço privado, tem uma explicação muito plausível. As mulheres negras são lidas como o corpo sem mente, passam por um processo de negação de sua própria humanidade. É o corpo açoitado, cobiçado e hipersexualizado. Logo, as violências contra esses corpos no Brasil sempre foram naturalizadas, razão pela qual a análise dos indicadores sociais de violência não causa tanta comoção social.

Foi justamente pela violência colonial e escravocrata que as mulheres negras tornaram-se o 'Outro', não humano, não civilizado, sem cultura, sem história, um objeto. "Negar a humanidade plena das mulheres, tratando-nos como o Outro objetificado em múltiplos binarismos, demonstra o poder que o pensamento binário, a diferença formada por oposições e a objetificação exercem nas opressões interseccionais." (COLLINS, 2019, p. 139). É este imaginário produzido pela violência colonial que inculca na estrutura social as imagens de controle que recaem sobre as mulheres negras.

Diante dessas análises é urgente aprimorar o debate sobre a violência contra as mulheres, partindo das visões decolonais e feministas que estendam um olhar crítico às construções institucionai racistas. É preciso transformar de forma crítica as instituições de apoio às mulheres vítimas de violência doméstica, assim como enfrentar o universalismo do sistema judiciário e o universalismo da própria Lei Maria da Penha, pois as redes operantes do patriarcado, do sexismo e do racismo são reais e profundas, totalmente desprendidas de qualquer análise crítica (SEVERI, 2017).

\section{O racismo institucional perpetuando mitos da branquitude}

Para compreender a construção do sujeito universal e as estruturas jurídicas operantes, é preciso refletir sobre o padrão estabelecido sobre quem se destina a proteção contida na expressão 'Direito Humanos'. Pela teoria crítica dos direitos humanos, Alejandro Rosillo Martínez (2019) apresenta alguns fundamentos ou usos desses direitos. Um dos fundamentos é o de que os direitos humanos possuem um caráter encantatório fixado a partir da estrutura normativa produzida pelo Estado e a partir dele. Ele é encantatório justamente por prever formalmente um catálogo ideal de direitos humanos, cujo uso funcional serve para manter o status quo. Outro fundamento dos direitos humanos é aquele que se constrói a partir dos processos de luta. Deve-se potencializar a legitimidade de mobilização a partir da sociedade, almejando romper e superar as desigualdades e as exclusões sociais. É particularmente neste uso e fundamento dos direitos humanos que este texto pretende se afirmar. Justamente por colocarmos o foco na trajetória de luta das mulheres negras e na construção do pensamento feminista negro e decolonial como uma abordagem epistemológica de resistência.

No Brasil, as pessoas crescem imersas com a ideia de viver em uma democracia racial. As pessoas brancas não se enxergam enquanto brancas, pouco discutem sobre branquitude, embora gozem de privilégios por meio da sua inserção em diferentes níveis hierárquicos. Nos espaços de intelectualidade, a branquitude acrítica reproduz a lógica colonialista que segue inferiorizando mulheres negras e negros. Isso ocorre por conta da designação do 'lugar do branco' e 'lugar do negro', demonstrando o racismo enraizado na academia e transportado para o sistema judiciário (CARDOSO, 2010).

O sistema judiciário é operado de forma a atender os interesses da elite, das pessoas brancas, ou de todas aquelas que adotam uma postura de manutenção ao status quo. Com isso, vale refutar a tese de neutralidade do sistema judiciário que flerta abertamente com o racismo. "Pessoas brancas controlam praticamente todas as instituições públicas e privadas deste país; isso permite que elas operem de acordo com os interesses do grupo racial dominante", com isso o acesso às esferas do judiciário é meramente ilustrativo, já que não atende a população de modo igualitário (OLIVEIRA; CARVALHO, 2020).

No Brasil, o sistema de justiça é lido como uma máquina que condena e marca os corpos negros. Os discursos insistem em diminuir os impactos na vida da comunidade negra - em especial das mulheres negras - alegando que os Direitos Fundamentais são assegurados pela Constituição Federal Brasileira de 1988, como se a formalização de direitos desse conta de desmantelar o racismo (OLIVEIRA; CARVALHO, 2020) 
Entender a operacionalização do racismo institucional no poder judiciário, e no sistema de justiça como um todo, é uma das formas de fraturar o padrão universalizante que segue erguendo obstáculos à população negra. Com a intensificação dos aparatos institucionais, as desigualdades são cada vez mais palpáveis, e ausência de discussão sobre branquitude, racismo, sexismo, por meio da universalização dos Direitos humanos, ampara escancaradamente decisões excludentes e hierarquizantes. Pires (2017) pontua ainda que o que tem acontecido sob a luz da 'democracia racial' é o silenciamento em massa do Poder Judiciário em relação às pessoas negras, já que foi estruturado para reproduzir o modelo patriarcal e escravista, que desumaniza e seleciona quem pode alcançar as ferramentas positivas institucionais. Ao refletir sobre a junção das entranhas racistas do poder judiciário e a violência doméstica, Pereira (2014, p. 31) diz:

A operação da ideologia racista no âmbito das relações sociais, da cultura, da economia e da política está vinculada à produção de construções sociais de gênero, organizadas por norma sociais que dividem os indivíduos entre os sexos femininos e masculinos e naturalizam relações de continuidade entre corpo, gênero, desejo/prática sexual e raça. Estas construções, combinadas de formas complexas, múltiplas e flexíveis à ideologia racista, estruturam un sistema de poder e privilégio da masculinidade e da branquitude.

Portanto, diante dessas colocações, esse orquestramento precisa ser reformulado e ressignificado. A atuação do Estado de forma conivente com as opressões patriarcais e racistas já eram observadas antes mesmo da criação da Lei Maria da Penha, pois houve o processo de esterilização em massa das mulheres negras, incentivo a imigração europeia e práticas outras de eugenia, demonstrando que há décadas o Estado segue operando por suas ferramentas cisheteronormativas, racistas e misóginas (PEREIRA, 2014).

\section{Conclusão}

Os feminismos negros e decolonial constituem uma necessidade para enfrentar as imposiçõe colonialistas, pois rompem com as construções eurocêntricas que seguem dialogando com histórias universalizantes e hierarquizantes. Essa ampliação possibilita a discussão do feminismo com os saberes produzidos em diversos espaços, como pontua bell hooks (2019), estimulando a elaboração de estratégias que sejam críticas, coletivas e inclusivas.

Ao situar a Lei Maria da Penha como um marco normativo para as mulheres, é preciso também incluir o acesso à justiça e ter em mente sua problematização. Para falar de acesso à justiça é necessário localizar o viés racista que emana de atitudes institucionais, e fundamental desmantelar o mito construído em torno da democracia racial. Com essa análise conjunta estabelecem-se compromissos com a realidade social e cultural das mulheres.

Para que ocorra a transformação dos órgãos que compõem o sistema de justiça, é urgente assumir uma postura de enfrentamento efetiva do sistema racista, patriarcal e cisheteronormativo. As mulheres só conseguirão acessar ao poder judiciário e às ferramentas de proteção quando houver um compromisso coletivo, uma luta definitivamente antirracista, antisexista e anticapitalista. Essas medidas podem e devem ser tomadas com a intersecção entre os conhecimentos e experiências do Estado produções nos ambientes acadêmicos, sistemas judiciários, comunidades e todos aqueles dispostos a contribuir com uma rede de apoio efetiva às mulheres vítimas de violências domésticas.

Além das contribuições aqui elencadas, frisa-se o compromisso da branquitude em promover espaços de debate sobre raça. Não só a branquitude precisa refletir de forma crítica, como os ambientes acadêmicos precisam possibilitar novos horizontes e perspectivas narradas por aqueles que são subalternizados pelas próprias hierarquias mantidas dentro desses espaços.

Apesar do avanço que a Lei Maria da Penha estabelece para algumas mulheres, há limites e barreiras dentro do sistema da ordem jurídico-positiva que dificultam o pleno funcionamento da Lei. Promover a comunicação entre as redes de atendimento às mulheres, garantir o acesso à justiça, formular e executar políticas públicas adequadas e focalizadas, são alternativas para ampliar as perspectivas a favor do enfrentamento das violências domésticas.

Com este breve ensaio pretendemos colocar as mulheres negras em pauta no debate sobre 
a violência doméstica no Brasil. Iniciamos a escrita nos perguntando: Por que enquanto os índices de violência doméstica contra mulheres brancas diminuem, os índices de violência doméstica contra mulheres negras aumentam no Brasil? Não foi nossa pretensão responder diretamente a esta questão, mas, a partir dela, trazer à tona o debate sobre a complexidade das relações raciais e de gênero na sociedade brasileira. Encerramos com pelo menos uma certeza, a de que políticas públicas universais e o discurso universal dos direitos humanos estampado nas normas jurídicas jamais serão capazes de produzir igualdades e romper com o ciclo de violência contra os corpos negros, iniciado aqui desde o século XV.

\section{Referências}

ALMEIDA, Silvio Luiz de. O que é racismo estrutural? Belo Horizonte, MG: Letramento, 2018.

CAMPOS, Carmen Hein de. Desafios na implementação da Lei Maria da Penha. Revista Direito GV [online], v. 11, n. 2, p. 391-406, jul-dez. 2015.

CARDOSO, Lourenço. $\mathrm{O}$ branco ante a rebeldia do desejo: um estudo sobre a branquitude no Brasil. 2014. 290 f. Tese (doutorado) - Universidade Estadual Paulista Júlio de Mesquita Filho, Faculdade de Ciencias e Letras (Campus de Araraquara), 2010.

CARNEIRO, Suelaine. Mulheres negras e violência doméstica: decodificando os números. 1. ed. São Paulo: Geledés Instituto da Mulher Negra, 2017.

CASTRO, Susana. Feminismo Decolonial. Princípios: Revista de Filosofia, Natal, v. 27, n. 52, jan.-abr. 2020, Natal.

COLLINS, Patricia Hill. Aprendendo com a outsider within: a significação sociológica do pensament feminista negro. Revista Sociedade e Estado. v. 31, n. 1 - jan/abril, p. 99-127, 2016.

COLLINS, Patricia Hill. Pensamento feminista negro: conhecimento, consciência e a política do empoderamento. Tradução Jamille Pinheiro Dias. São Paulo: Boitempo, 2019.
CONSELHO FEDERAL DE SERVIÇO SOCIAL. Disponível em: <http://www.cfess.org.br/>.

IGUEIREDO, Angela. Epistemologia insubmissa feminista negra decolonial. Tempo e Argumento Florianópolis, v. 12, n. 29, e0102, jan./abr. 2020.

FÓRUM BRASILEIRO DE SEGURANÇA PÚBLICA. Visível e invisível: A vitimização de mulheres no Brasil. 2a Ed, v.6, 2019.

GONZALEZ, Lélia. Por um feminismo Afro-latino americano. Organização de Flavia Rio e Márcia Lima. 1. ed. Rio de Janeiro: Zahar, 2020.

HOOKS, Bell. Teoria feminista: Da margem ao centro. São Paulo, Perspectiva. 2019.

INSTITUTO MARIA DA PENHA. Disponível em: <https://www.institutomariadapenha.org.br/>. 2018.

KIEFER, Cristian da Silva; SEABRA, Débora Totini, JÚNIOR, Luiz Antônio Soares. Feminismo violência e poder: uma análise histórico-jurídica da trajetória e dos documentos que culminaram na lei maria da penha e no feminicídio. Cadernos do Programa de Pós-Graduação em Direito PPGDir/UFRGS, Porto Alegre, v. 11, n. 3, 2016.

KILOMBA, Grada. Memórias da plantação: episódios de racismo cotidiano. 1 Ed. Rio de Janeiro: Cobogó, 2019.

LEMOS, Rosália de Oliveira. Os feminismos negros: a reação aos sistemas de opressões. Revista Espaço Acadêmico. Maringá/PR, n. 185, out., 2016.

LIMA, Fernanda da Silva; SOUSA, Leandra da Silva. Por uma epistemologia feminista negra decolonial desde às margens no Brasil. 2021. (mimeo)

LIMA, Fernanda da Silva; SILVA, Karine de Souza. Teorias críticas e estudos pós e decoloniais à brasileira: quando a branquitude acadêmica silencia raça e gênero. Empório do direito, São Paulo, jun. 2020.

LUGONES, María. Colonialidad y Géreno. Tabula Rasa. Bogotá, Colômbia, n. 9, p. 73-101, jul. -dic., 2008. 
MARTÍNEZ, Alejandro Rosillo. Minicurso sobre teoria crítica dos direitos humanos. II Seminário Internacional em Direitos Humanos e Sociedade e IV Jornada de Produção Científica em Direitos Fundamentais e Estado. Criciúma: PPGD/UNESC, 2019.

MELO, Paula et al. Descolonizar o feminismo. Brasília: Editora FB, 2019.

MOREIRA, Núbia Regina. Feminismo negro brasileiro: igualdade, diferença e representação. Anais do 31 ${ }^{\circ}$ Encontro da Anpocs. Caxambu/MG: Anpocs, 2007.

OLIVEIRA, Lucas; CARVALHO, Marcos. Como o racismo guia a Justiça brasileira. Ponte Jornalismo São Paulo, abril, 2020.

ZIMERMAN, Artur. Os ‘Brasis’ e suas desigualdades. Santo André, SP: Universidade Federal do ABC, 2017.

PETRONE, Talíria. Prefácio à edição brasileira. In: ARRUZZA, Cinzia; BHATTACHARYA, Tithi; FRASER, Nancy. Feminismos para os 99\%, um manifesto. Tradução de Heci Regina Candiani. São Paulo: Boitempo, 2019.

PIRES, Thula. Direitos humanos traduzidos em pretuguês. 13th Mundo de Mulheres \& Fazendo Gênero 11, 1-12. Florianópolis: UFSC, 2017.

SANTOS, Vívian Matias dos. Notas desobedientes: decolonialidade e a contribuição para a crítica feminista à ciência. Psicologia \& Sociedade, [s.l.], v. 30, 3

SEVERI, Fabiana Cristina. Enfrentamento à violência contra as mulheres e à domesticação da Lei Maria da Penha: elementos do projeto jurídico feminista no Brasil. Ribeirão Preto, SP, 2017. 